Article

\title{
Thermal and Vibration Comfort Analysis of a Nearly Zero-Energy Building in Poland
}

Małgorzata Fedorczak-Cisak ${ }^{1, *}$, Marcin Furtak ${ }^{1, *}$, Jolanta Gintowt ${ }^{2}$, Alicja Kowalska-Koczwara ${ }^{3}$, Filip Pachla ${ }^{3}$, , Krzysztof Stypuła ${ }^{3}$ and Tadeusz Tatara ${ }^{3}$ (D)

1 Malopolska Laboratory of Energy Efficient Building, Faculty of Civil Engineering, Cracow University of Technology, 31-155 Cracow, Poland

2 Institute of Materials and Construction Structures, Faculty of Civil Engineering, Cracow University of Technology, 31-155 Cracow, Poland; jgintowt@pk.edu.pl

3 Institute of Structural Mechanics, Faculty of Civil Engineering, Cracow University of Technology, 31-155 Cracow, Poland; akowalska@pk.edu.pl (A.K.-K.); fpachla@pk.edu.pl (F.P.); kstypula@pk.edu.pl (K.S.); ttatara@pk.edu.pl (T.T.)

* Correspondence: mfedorczak-cisak@pk.edu.pl (M.F.-C.); mfurtak@pk.edu.pl (M.F.); Tel.: +48-696-046-050 (M.F.-C. \& M.F.)

Received: 31 August 2018; Accepted: 15 October 2018; Published: 18 October 2018

check for updates

\begin{abstract}
Placing emphasis exclusively on minimizing energy consumption in low-energy buildings can adversely impact thermal comfort and vibrational comfort. Vibrational comfort is extremely important in building design, especially within mining or seismically active territories, and due to car transportation in city centers. In this article, a new approach to designing passive buildings and nearly zero-energy buildings (NZEBs) in Poland is proposed, which has a strong emphasis on the necessity of providing comfort of use in passive houses and NZEBs. Additionally, vibration comfort provisions in the design process are examined. The research gap that will be addressed by the research presented in this article is to extend the comfort conditions of passive buildings and NZEBs into the area of vibratory comfort. The second goal of the project is to determine the impact of solar control systems on the conditions of thermal comfort. The conclusions from the research will allow for the optimization of design assumptions for passive houses and NZEBs. The conclusions from the tests can serve as the basis for introducing appropriate construction law requirements in Poland. The results of the research, which are presented in the article, indicate that the technical requirements that are applicable in Poland ought to include requirements regarding the use of sun blinds in NZEBs and passive buildings (not only as recommendations). In particular, the use of apertures on the south side ought to be mandated. The article can also be the basis for introducing the requirements of vibration comfort to the PN-EN 15251:2012 “Indoor environmental input parameters for design and assessment of energy performance of buildings addressing indoor air quality, thermal environment, lighting and acoustics" standard, which is the basis for designing the parameters of the internal environment for buildings.
\end{abstract}

Keywords: sustainable building; energy efficient building; NZEB; thermal comfort; vibrational comfort

\section{Introduction}

In recent years, the construction sector has placed an emphasis on designing and constructing lower energy consumption buildings. Apart from strength and durability criteria, minimizing energy consumption has become in Poland one of the main design criterions for buildings. More and more stringent requirements for buildings in European countries strive to introduce a standard of buildings with nearly zero energy consumption (NZEB). In addition to minimizing energy consumption in 
low-energy buildings, it is very important to ensure comfort of use in buildings [1]. Buildings of nearly zero-energy consumption (NZEB) and passive houses can be all placed under the umbrella term of low-energy buildings. NZEB buildings are a construction standard that was introduced by Directive 2010/31/UE [2]. The standard for passive houses is determined by the Passive House Institute in Darmstadt (Germany) [3].

A defining characteristic of low-energy buildings (both passive and NZEB), is an airtight outer layer (external walls, windows, doors, floor, and roof) characterized by a very high heat resistance and low demand for utility energy. The requirements within this scope are set out in the technical and construction regulations that are in force in various countries. In Poland, the regulations regarding the energy efficiency of buildings are set out in the "Regulation of the Minister of Infrastructure and Construction regarding Technical Requirements which should be met by buildings and their location 2018" [4]. Passive buildings are very common in Europe, i.e., Austria or Germany. However, there are not many passive buildings in Poland. Tests carried out in some passive buildings show that there is a problem regarding room overheating.

Minimizing energy consumption is the primary requirement for NZEB houses. Polish requirements included in the technical provisions for NZEBs do not determine specific requirements pertaining to comfort levels in buildings. That being said, in "Regulation of the Minister of Infrastructure and Construction Regarding Technical Requirements Which Should Be Met by Buildings and Their Location" [4], a general provision was included pertaining to ensuring thermal comfort that reads: "a building should be designed and constructed in a way that limits the risk of the building overheating in the summer period" as well as a requirement pertaining to the maximum window surface with a coefficient of $\mathrm{U}$ (Heat transfer coefficient) $>0.9\left(\mathrm{~W} / \mathrm{m}^{2} \mathrm{~K}\right)$. However, these requirements cannot guarantee the provision of comfort of use in buildings. Several publications contain information on overheating low-energy buildings. The results that are presented in this article also indicate such a problem. Primary requirements for passive houses also fail to deliver guidelines for providing conditions of use comfort. The conclusions from the research will allow the optimization of the design assumptions for passive and NZEB buildings. The conclusions from the tests can be the basis for introducing appropriate requirements in the construction law in Poland.

Thermal comfort is one of the most important problems in the design of NZEB and passive buildings. In turn, vibration comfort is often overlooked in the building design. The existing standard that applies to multiple aspects of the comfort of use of buildings [5] avoids vibratory comfort. A favorable energy balance in buildings takes into consideration only factors affecting the energy consumption, but does not include factors that impact the usage comfort in apartments. Designers of passive houses and NZEBs frequently utilize glass glazing as an element to acquire heat energy. Vast glazing, especially south-facing, can-in favorable conditions-significantly improve the energy balance of a building. At the same time, taking into consideration an airtight building envelope with high heat resistance, solar gains-especially in the summer-are a cause of significant room overheating.

The research undertakes answering the two following questions: "Is it necessary, in addition to the thermal comfort in NZEB buildings, to check vibratory comfort?" "What influence do shading systems have on thermal comfort in NZEB buildings?"

In article (Kisilewicz) [6], the author concludes that in buildings characterized by a very low energy demand, in addition to the radical minimization of heat losses, the trend is to obtain maximum solar gains by orientating toward south-facing windows. Increasing the participation of renewable energy in the building's heat balance is possible, in part, by the rational passive utilization of solar energy. According to Kisilewicz, the expectations and emphasis placed on low heating requirements both often result in intense interior overheating, or the necessity of energy-inefficient cooling. In his work, Kisilewicz carried out an analysis of energy consumption for a building of a higher thermal insulation and a passive house, depending on the window size. As the result of the analyses, it is concluded that vast glazings, which are frequently used by designers, can lead-in the summer period-to excessively high interior temperatures (more than $27^{\circ} \mathrm{C}$ ) for over $70 \%$ of the summer 
period. Vast glazings, especially in office buildings, are the sign of a modern and luxurious design in today's architecture. Buildings with glazed elevations are delivered both as public utility buildings and as residential estates.

The analysis (Bzowska, D.) [7] of 24-h interior temperature ranges in buildings with very high external partition insulation for a single-family house (passive houses and NZEBs) were determined for the summer period. In this analysis, the authors (Bzowska) pointed out that energy-efficient buildings, which are often lacking in significant accumulation mass and equipped with a natural ventilation system, are overheating during the summer. Additionally, the authors pointed out that according to the A1F1 scenario, the average temperature will increase on average by $40{ }^{\circ} \mathrm{C}$ in the 21st century [8]. Ensuring an appropriate level of thermal comfort in new and modernized buildings is one of the more important elements of building design and construction. Passive houses and NZEBs must meet the thermal comfort requirements not only right now, but also throughout the period of the predicted climate warming. The overheating of rooms, especially in the summer period, is the subject of research and analyses that have been carried out in low-energy and passive buildings. In the article [9] (Dudzińska), the author researched the impact of a transparent partitions surface on the microclimate of a passive public building. The test period was set from 15 August 2002-22 August 2002, when the biggest threat of overheating is present in Poland. The windows that were used in the tests have the heat transfer coefficient of $\mathrm{U}=0.79 \mathrm{~W} / \mathrm{m}^{2} \mathrm{~K}$. Total radiation transmittance factor was $\mathrm{g}=0.49$ (without a unit). For the research, internal blinds and external light breakers were installed. The author (Dudzińska) considered five variants, assuming different sizes of glass surfaces on the southern side from "total glazing" to "no glazing" variants. The results obtained from the Design Builder modeling software showed that in the case of "total glazing", the interior temperature would exceed $29^{\circ} \mathrm{C}$ (predicted mean vote $\left.(\mathrm{PMV})<2.0\right)$. In the case of "no glazing" on the south facade, the author (Dudzińska) received an internal temperature value of approximately $23^{\circ} \mathrm{C}(\mathrm{PMV}<1.0)$. In article [1], the author (Dudzińska) analyzed the influence of various sun blinds on the comfort level in a passive, public utility building. Analyses were carried out in the Design Builder simulation software for the summer period between 1 May 2015 and 30 August 2015. The best level of comfort has been attained by the author (Dudzińska) for the variant that used external sun blinds in the form of sun breakers. The difference between the maximum temperatures for the analyzed variants-one without blinds and one with blinds-was at the level of $0.52^{\circ} \mathrm{C}$, assuming a mechanical vent-exhaust ventilation. Despite small temperature differences in the selected variants, the average value of the PMV factor for the best variant (external breakers without interior shutters) equaled 0.83 , which was in violation of the accepted norm set at [10] (Fanger) as $-0.5<\mathrm{PMV}<+0.5$. Additionally-in the analysis-using interior shutters caused the increase in lighting energy consumption by about $70 \%$. The interior building environment (comfort) has a significant influence on the health and well-being of the users [7] (Bzowska). Ensuring comfortable conditions increases the productivity of work performed both in office and residential buildings. A Danish scientist, Ole Fanger, was the pioneer of research into the thermal comfort of users. In 1973, he published his first work pertaining to the influence of weather conditions on the residents of buildings. Fanger's research used two main indicators for analyzing occupants' comfort: PMV (predicted mean vote) and PPD (predicted percentage of dissatisfied) [10]. Both those indicators serve as the basis for the further development of the two most extensive models of thermal comfort. Work on an adaptive comfort model, based on the analysis of field research, was carried out by [11] (Shukuya). An adaptive model takes into consideration a weighted average working exterior temperature. The analysis [12] (Prek), on the other hand, described why passive technology measures (such as the better thermal insulation of exterior building envelope systems and the more efficient solar control of window systems) come as the top priority, from the findings that are available from a series of human-body exergy research. In such a case, where the room air temperature is higher than the conventional target value in mechanical air cooling, the smallest possible human-body exergy consumption rate emerges with the mean radiant temperature ranging between $26-29{ }^{\circ} \mathrm{C}$ [13]. In the analysis, attention was paid to increases in the mortality rate caused by high temperatures. According 
to the Institute of Work Medicine in Łódź [14], comfortable ambient temperatures for light work in a sitting position during the summer should not exceed $23.9-26.7^{\circ} \mathrm{C}$. Research and analyses into ensuring thermal comfort were the basis for developing several of the current standards pertaining to comfort such as ASHRAE 55: 2013 [15], ISO 7730: 2005 [16], and EN 15251: 2007 [5]. Thermal comfort is an issue described in the standards [5,16] and in few publications [17-20]. Published work usually cover one area of interest pertaining to the comfort of a building's usage. Buildings are designed separately in terms of thermal comfort criteria, acoustic comfort criteria, lighting comfort, and air quality. Only norm PN-EN 15251: 2012 “input parameters of the interior environment pertaining to the design and evaluation of energy characteristics of buildings, including interior air quality, thermal environment, lighting, and acoustics" [5] introduces the rules for providing comfort in newly designed and modernized buildings across several simultaneous aspects. However, the quoted norm does not take into account vibrating comfort. This aspect of comfort should be taken into account, because as it was mentioned in the introduction, vibrational comfort can pose health problems. Materials used for the assurance of thermal comfort can also be used to ensure vibrational comfort, but this needs to be investigated. This is why a multidisciplinary approach is needed. The measurements that are made and shown in this article indicate the need for multicriterion optimization, which can provide requirements not only for NZEB, but for all buildings.

The introduction of the standard of NZEB and passive buildings means the implementation of the climate and energy package by 2020. The 2020 package is a set of binding rules to ensure that the European Union (EU) achieves its climate and energy goals by the year 2020. The authors of this paper propose the introduction of rules for designing low-energy buildings (passive and NZEB) in order to ensure the conditions of comfort in several areas simultaneously. Additionally, the aim of this article is to show that vibration comfort is very important when designing NZEB and passive buildings (Figure 1).

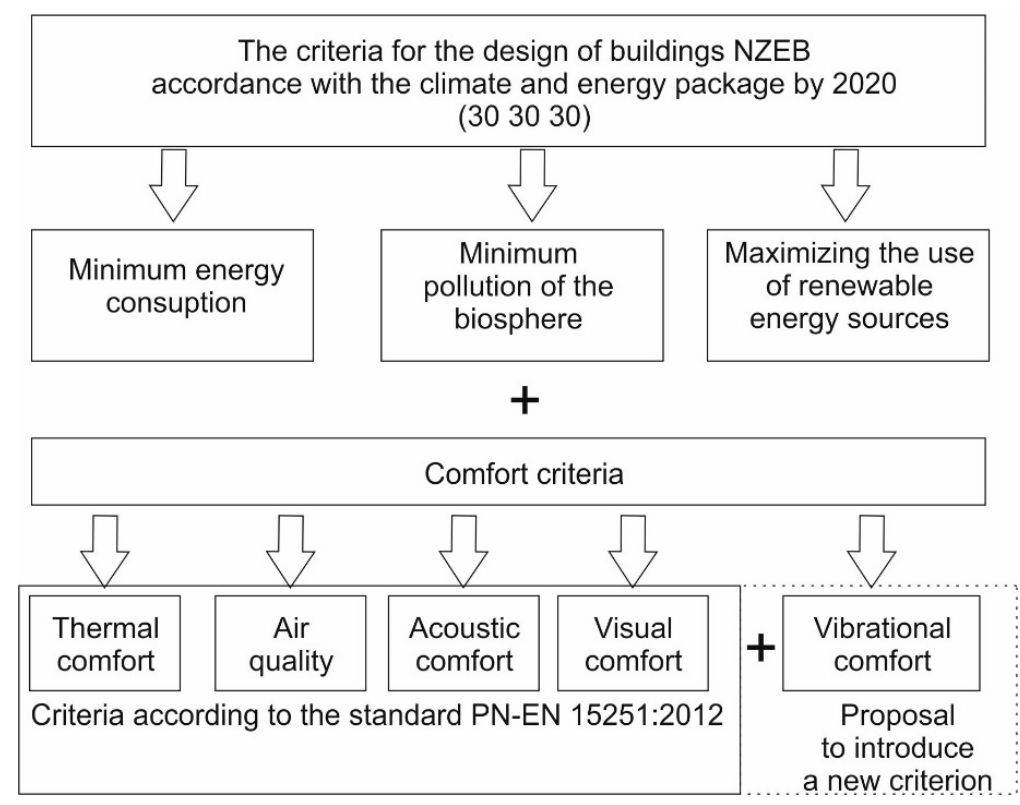

Figure 1. The criteria considered in designing nearly zero-energy buildings (NZEBs) (authors' own source).

One of the aspects of comfort in a room is vibratory comfort, which is often overlooked by designers and engineers due to a lack of requirements for investors. Taking into account such requirements is associated with an increase in the construction costs of buildings. This is due to the need to design, among others, barriers in the ground that limit the transmission of vibrations to building structures or special, expensive vibroisolation. However, if the level of vibration comfort that is specified in the standard is exceeded, it may pose a problem for human health [21,22]. In such cases, 
it may lead to an uneven influence of vibrations on the internal organs of the human being and, as a consequence, the occurrence of patients that are for example connected with the circulatory system and metabolic disorders. For example, frequencies in the range of 10 to $18 \mathrm{~Hz}$ can cause frequent urination, in the range of $13-20 \mathrm{~Hz}$ can influence speech, and very low values of frequencies $(5-7 \mathrm{~Hz})$ can provide chest pains. Therefore, it may cause permanent damage to health and additional costs associated with the treatment of the resulting ailments. Consequently, it can cause permanent damage to health and incur additional costs. Specific types of infrastructure, such as metro systems, are always monitored so as not to disturb the comfort conditions in the rooms, in particular acoustic and vibratory regulations [23,24] (Han 2016, Liang 2015). Trams are now frequently monitored, especially in city centers [25] (Cik 2014), and systems for 24-h vibration monitoring are established.

Problems are apparent when road infrastructure is considered. Traffic conditions change over the course of decades; there are increasing amounts of vehicles on our roads. Higher traffic intensity can cause higher levels of vibration: this could constitute a health risk as mentioned above for residents living in buildings that are located nearby. The health risks are not always just psychological; they may sometimes be physiological as well [26,27] (Croy 2013, Smith 2013).

Vibration is often neglected when considering indoor conditions. However, the perception of vibrations in buildings can be very annoying to occupants, as we mentioned above. The authors' approach to the issue of the multi-aspect comfort of use of NZEB buildings is novel because of their expanding the range of assessment criteria with the criterion of vibratory comfort.

In this article, vibrational comfort is described, and as an example, the results of measurements made in one of the rooms in a near-zero energy building are shown. The general methodology and example results of vibration measurements are presented below.

\section{Materials and Methods}

The first step in determining the optimal conditions for the multi-criteria comfort of NZEBs is to conduct research in natural conditions. The tests were carried out in the Malopolska Laboratory of Energy Efficient Building (MLBE). The MLBE building is an experimental building, and it is a dedicated research facility that is divided into 14 zones in which the internal environmental conditions can be manipulated independently. The building is designed in a way that enables carrying out in situ tests.

\subsection{The Criterion for Ensuring Thermal Comfort}

In the in situ studies on thermal comfort, the influence of sun blinds on the change of the interior environmental parameters was taken into account. The tests were carried out in two comparable rooms located in the MLBE building: rooms P1.06 and P2.04 (Figure 2). Room P1.06 has a south-facing glass façade with a heat transfer coefficient $\mathrm{U}=0.9\left(\mathrm{~W} / \mathrm{m}^{2} \mathrm{~K}\right)$ and coefficient $\mathrm{g}=0.6$ (without a unit). The room is adjacent to three other rooms where a constant temperature of $22^{\circ} \mathrm{C}$ was maintained.

Room P2.04 also has a south-facing glass façade with a heat transfer coefficient of $U=0.9\left(\mathrm{~W} / \mathrm{m}^{2} \mathrm{~K}\right)$ and coefficient of $g=0.6$ (without a unit). The façade has a system of external blinds with the possibility of adjusting the position of the lamellas. As with room P1.06, the room is adjacent to three other rooms where a constant temperature of $22^{\circ} \mathrm{C}$ was maintained.

Studies were carried out using a system of sensors to measure the environmental quality (Figure 3). The measurements were in agreement with standards [16,28]. According to the norm [16], PMV, and PPD, indicators can be determined in three different ways:

(a) from equations, through computer simulations, e.g., in BASIC (the norm gives the formula for the program);

(b) directly from the tables included in the norm [16]; these values are estimated values;

(c) measured directly with an integrated sensor. 
In this paper, the last method was used, based on direct measurement with the use of an integrated sensor.

According to the methodology described by standards [5,16], measurements should be made in typical rooms and during typical periods of use. The category of the internal environment should be assessed on the basis of the temporal or spatial distribution of temperatures in the room. Measuring points and instruments meet the requirements of standard [5].

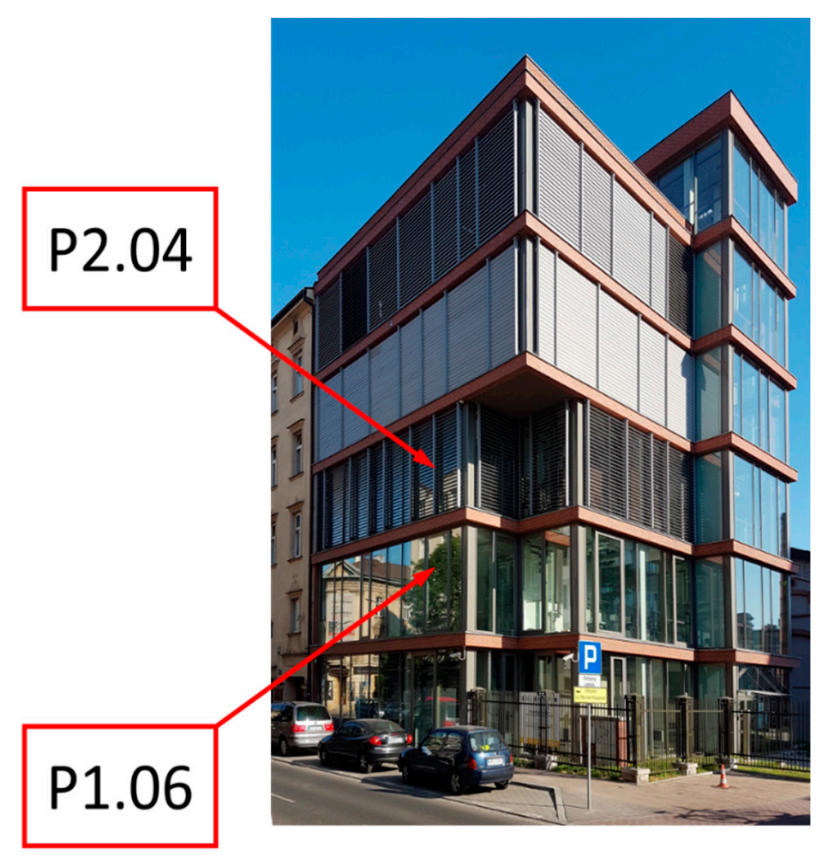

Figure 2. View of the building (southeast (S-E) elevation) with rooms in which studies were carried out. Room P2.04 is equipped with a system of external solar blinds.

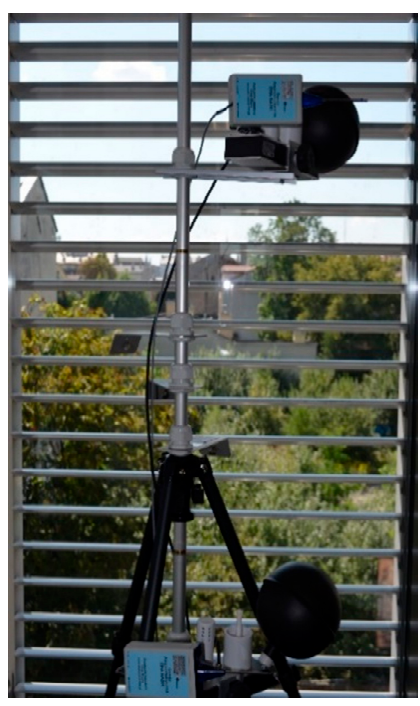

(a)

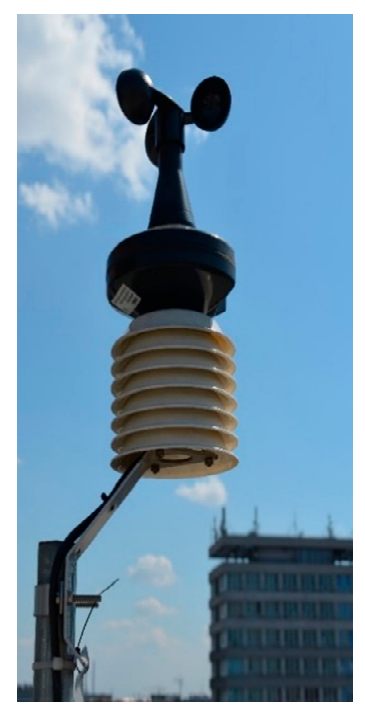

(b)

Figure 3. Testing equipment: (a) equipment to test thermal comfort; (b) equipment to test external environmental parameters

The standard [16] does not specify the length of the measurement period-this is described by standard [5]. The tests were carried out in the summer season. In accordance with the literature quoted in the Introduction, the summer season is the most challenging period to manage the right thermal comfort in rooms. 
The recommendations given by standard [5] in relation to the length of measurements determine the representative period as "sufficiently long", e.g., 10 days. The authors conducted a series of tests in the period of time between 1 August and 10 August 2017. The selected period of time adequately fulfills the requirements contained in standard [5].

The tests were carried out using measuring equipment that meets the PN-EN 7726 [28] standard. The measuring equipment (Figure $3 \mathrm{a}$ ) is a microclimate meter.

The measured parameters were:

- ta-air temperature measurement;

- tg-temperature of blackened sphere (heat radiation meter) - the black sphere, in agreement with the norms, should be $15 \mathrm{~cm}$ in diameter;

- tnw-natural wet-bulb temperature measurement;

- $\mathrm{RH}-$ measurement of relative air humidity;

- Va-measurement of air flow speed.

The frequency of data collection was every $1 \mathrm{~min}$.

The data from the sensors are given in Table 1.

Table 1. Sensors' data.

\begin{tabular}{cccc}
\hline Type of Sensor & Measurement Range & Scale & Accuracy \\
\hline Temperature sensors & $\begin{array}{c}-20{ }^{\circ} \mathrm{C}+50{ }^{\circ} \mathrm{C}(\text { wet } \\
\left.\text { thermometer } 0{ }^{\circ} \mathrm{C}+50{ }^{\circ} \mathrm{C}\right)\end{array}$ & $0.01{ }^{\circ} \mathrm{C}$ & $\pm 0.4{ }^{\circ} \mathrm{C}$ \\
\hline Humidity sensors & $0-100 \%$ & $0.1 \mathrm{RH}$ (relative humidity) & $\pm 2 \% \mathrm{RH}$ (relative humidity) \\
\hline Air velocity sensors & $0-5 \mathrm{~m} / \mathrm{s}$ & $0.01 \mathrm{~m} / \mathrm{s}$ & for $0-1 \mathrm{~m} / \mathrm{s}+/ 0.05+0.05 \times$ \\
\end{tabular}

On the basis of measurements, thermal comfort parameters were calculated from Formulas (1) and (2).

Designated parameters are:

- $\quad$ PMV—-predicted average thermal comfort rating [16]

- $\quad$ PPD—-predicted percentage of dissatisfied people [16]

$$
\begin{gathered}
\mathrm{PMV}=[0.303 \times \exp (-0.306 \times \mathrm{M})+0.028] \times\left((\mathrm{M}-\mathrm{W})-3.05 \times 10^{-3} \times\left[5733-6.99 \times(\mathrm{M}-\mathrm{W})-\mathrm{p}_{\mathrm{a}}\right]\right. \\
-0.42 \times[(\mathrm{M}-\mathrm{W})-58.15]-1.7 \times 10^{-5} \times \mathrm{M} \times\left(5867-\mathrm{p}_{\mathrm{a}}\right)-0.0014 \times \mathrm{M} \times\left(34-\mathrm{t}_{\mathrm{a}}\right) \\
\left.-3.96 \times 10^{-8} \times \mathrm{f}_{\mathrm{cl}} \times\left[\left(\mathrm{t}_{\mathrm{cl}}+273\right)^{4}-\left(\mathrm{t}_{\mathrm{r}}^{-}+273\right)^{4}\right]-\mathrm{f}_{\mathrm{cl}} \times \mathrm{h}_{\mathrm{c}} \times\left(\mathrm{t}_{\mathrm{cl}}-\mathrm{t}_{\mathrm{a}}\right)\right) \\
\mathrm{t}_{\mathrm{cl}}=35.7-0.028 \times(\mathrm{M}-\mathrm{W})-\mathrm{I}_{\mathrm{cl}}\left\{3.96 \times 10^{-8} \times \mathrm{f}_{\mathrm{cl}} \times\left[\left(\mathrm{t}_{\mathrm{cl}}+273\right)^{4}-\left(\mathrm{t}_{\mathrm{r}}^{-}+273\right)^{4}\right]+\mathrm{f}_{\mathrm{cl}} \times \mathrm{h}_{\mathrm{c}} \times\left(\mathrm{t}_{\mathrm{cl}}-\mathrm{t}_{\mathrm{a}}\right)\right\}
\end{gathered}
$$

where:

M-the amount of metabolism $\left(\mathrm{W} / \mathrm{m}^{2}\right)$

$\mathrm{W}$-the density of energy loss in the form of mechanical work $\left(\mathrm{W} / \mathrm{m}^{2}\right)$

$\mathrm{I}_{\mathrm{cl}}$-clothing insulation $\left(\mathrm{m}^{2} \mathrm{~K} / \mathrm{W}\right)$

$\mathrm{f}_{\mathrm{cl}}$-surface of clothes $\left(\mathrm{m}^{2}\right)$

$\mathrm{t}_{\mathrm{a}}$ - air temperature $\left({ }^{\circ} \mathrm{C}\right)$

$\mathrm{t}^{-} \mathrm{r}$-average radiation temperature $\left({ }^{\circ} \mathrm{C}\right)$

$\mathrm{t}_{\mathrm{cl} \text { - }}$ temperature of the clothes surface $\left({ }^{\circ} \mathrm{C}\right)$

Similarly, from Formula (2), the PPD indicator was set as the "expected percentage of dissatisfied", and was defined as the percentage of people who are very unhappy with the thermal conditions of the room:

$$
\text { PPD }=100-95 \exp (-0.03353 \text { PMV4 - 0.2179 PMV2) }
$$


External environmental parameters were collected from weather stations located on the roof of the laboratory building and on its south elevation (Figure $3 b$ ).

\subsection{The Criterion for Ensuring Vibrational Comfort}

The study included measurements of accelerations in control points of the analyzed building. Control points were set in accordance with the Polish code [29] and ISO standard [30]. They were placed at locations where occupants perceive vibrations. In all of the cases, accelerations were measured in each point in three orthogonal directions $(x, y$, and $z)$. The measurements were taken for a period of $24 \mathrm{~h}$. The locations of measurements points with accelerometers were used to estimate the human vibration perceptivity ratio, and are presented in Figure 4 . The points were located on the floor at the points where the vibrations of the floor are the greatest-mostly at the center of the floor slab. Accelerometers were placed on a plate, which is standard for this kind of measurement, as is described in PN-B-02171:2017-06 [29].

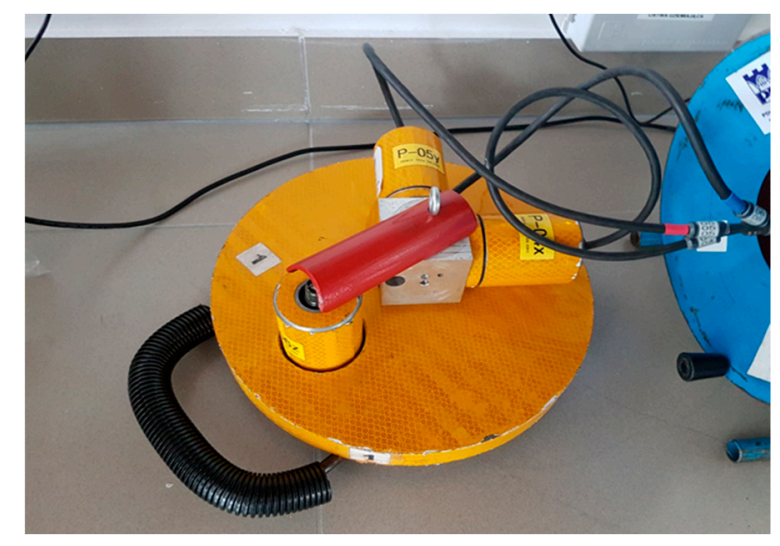

Figure 4. Accelerators in three directions ( $x, y$, and $z)$.

The following specialized apparatus was used in the research to measure the accelerations and vibration frequencies of the building:

- 393B12 type piezoelectric accelerometers PCBs;

- the ESAM Traveler Plus electronic data registration system;

- PA16000 EC Electronics signal conditioning system;

- LMS SCADAS Mobile analyzer (recording and analyzing system);

- measurement data analysis software (Matlab 7.3).

Measuring devices were fitted to measure the low-frequency vibrations that occur in the case of ambient vibrations.

The analysis of measurements was performed according to the RMS procedure, which is described in standards $[29,30]$.

\section{Results}

\subsection{Result of Tests the Thermal Comfort. Comparison of Prevailing Conditions in Rooms P1.06 and P2.04}

The test results, in accordance with the methodology contained in PN-EN 15251:2012, PN-EN 7726 [5,28], cover the summer period between 1 August 2017 and 10 August 2017 (10 days). The tests, which were conducted in a representative measurement period, include the measurement of temperature, humidity, and PMV. The measurements were carried out in two rooms, P.1.06 and P2.04 (Figure 2). Room P2.04 was equipped with an external shutter system. 
The following chart in Figure 5 shows the temperatures during the reference period. The chart in Figure 6 shows the humidity in the rooms. Figure 7 shows the assessment of thermal comfort determined using the PMV indicator.

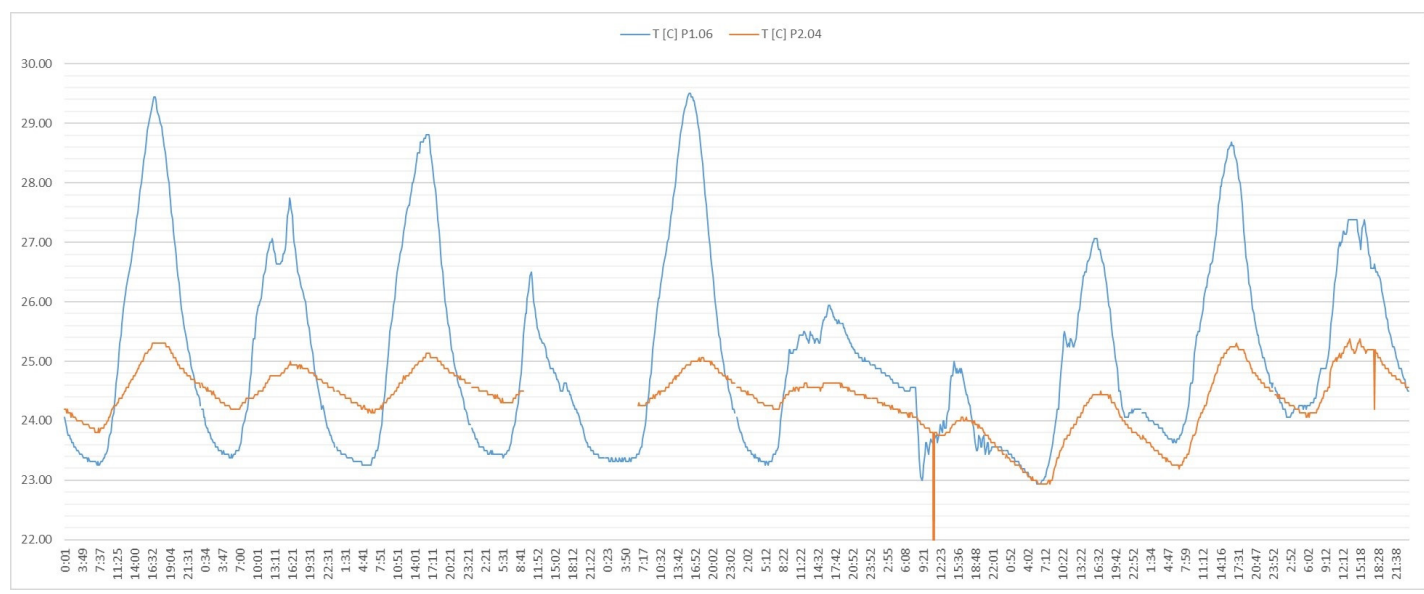

Figure 5. Temperature measurements in test rooms P1.06 and P2.04 during the reference period between 1 August 2017 and 10 August 2017.

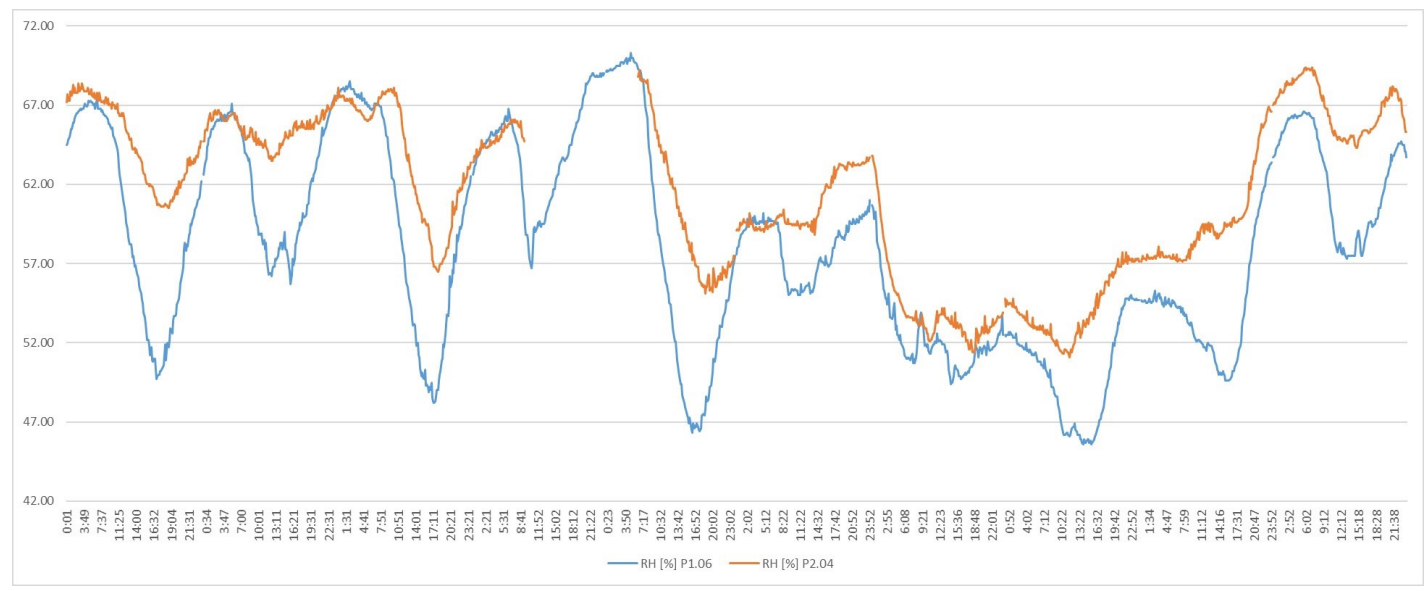

Figure 6. Humidity measurements in test rooms P1.06 and P2.04 during the reference period between 1 August 2017 and 10 August 2017.

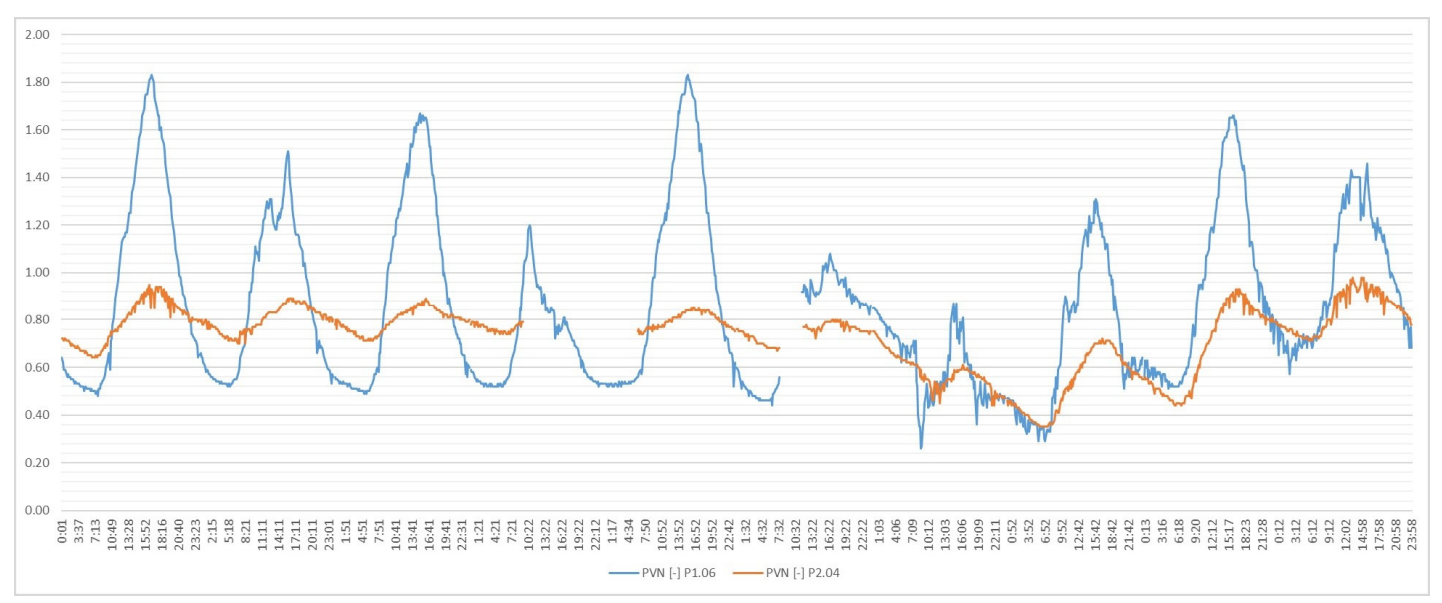

Figure 7. Calculations of the thermal comfort indicator of the predicted mean vote (PMV) (without a unit) in test rooms P1.06 and P2.04 during the reference period between 1 August 2017 and 10 August 2017. 
The detailed analyses were carried out using measurements of a day selected from the reference period. For the detailed analyses, the authors selected one representative day of measurements (1 August 2017) because of the maximum temperature that was reached both at the outside weather station and the inside room, P1.06. The highest temperature recorded in the period between 1 and 10 August 2017 at the weather station was $38.9\left({ }^{\circ} \mathrm{C}\right)$, while the highest temperature in P1.06 room was $29.44\left({ }^{\circ} \mathrm{C}\right)$.

Diagrams 5, 6, and 7 show the measurement discontinuities that were caused by temporary technical breaks. Figure 5 shows temperature measurements in test rooms P1.06 and P2.04 during the reference period between 1 August 2017 and 10 August 2017. Figure 6 shows humidity measurements in test rooms P1.06 and P2.04 during the reference period between 1 August 2017 and 10 August 2017. Figure 7 shows thermal comfort indicator of the predicted mean vote (PMV) (without a unit) in test rooms P1.06 and P2.04 during the reference period between 1 August 2017 and 10 August 2017.

The graphs below show the temperature changes in both rooms as well as the influence of temperature on the PMV comfort indicator (1 August 2017).

To aid the viewing of the temperature differences between the rooms, a similar range was adopted on the vertical axes (Figures 8 and 9). The first major difference is the stability of the temperature in room P2.04, which was equipped with external blinds that were, in this case, set in the 'open' position (Figure 9).

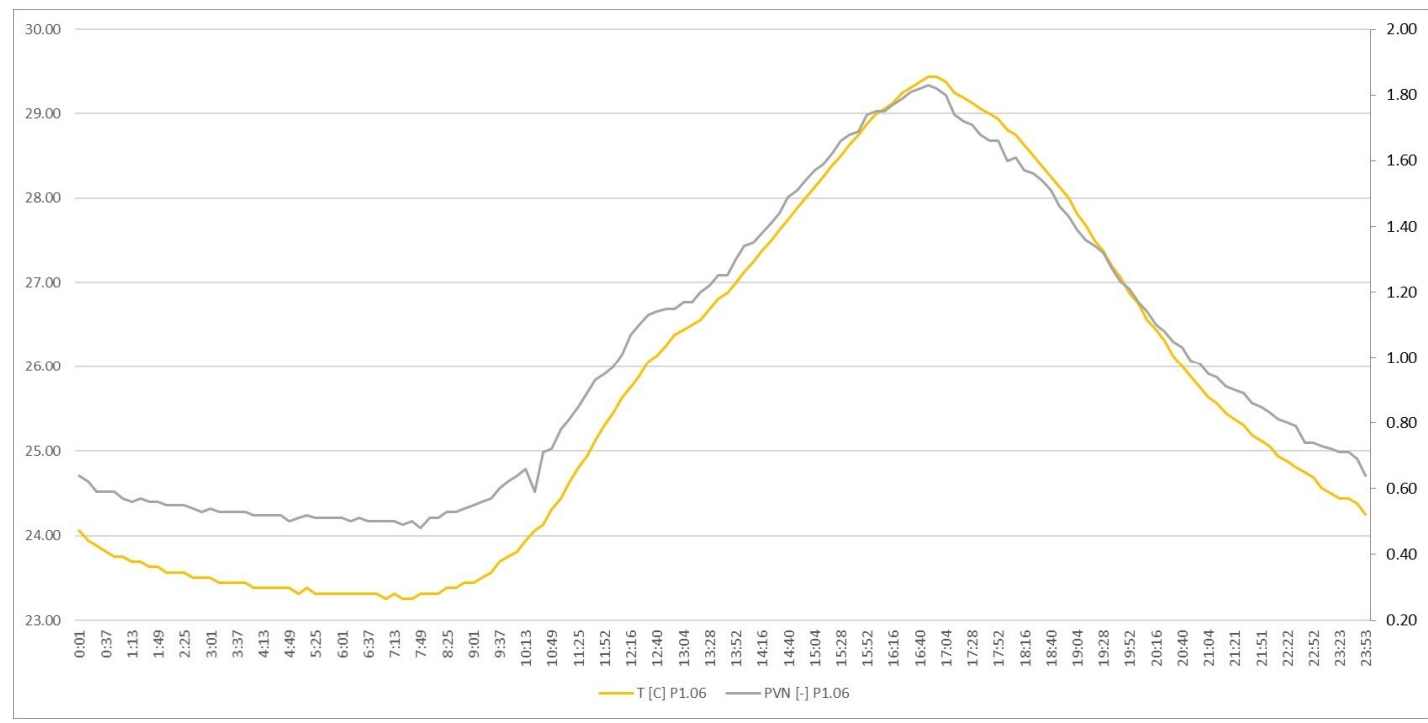

Figure 8. PMV and temperature relationship in the tested room P1.06 (1 August 2017).

The heating system, when working according to the schedule, is programmed in such a way that the temperature of $24^{\circ} \mathrm{C}$ can be obtained in both rooms. Room P1.06 was characterized by very unstable temperature; in the best case, this is around $23.2{ }^{\circ} \mathrm{C}$; in the worst case, it is around $29.5^{\circ} \mathrm{C}$ (Figure 8).

Room P2.04 is characterized by a very stable temperature, oscillating around $24-25^{\circ} \mathrm{C}$. This is illustrated in Figure 9.

Thermal comfort is function of temperature. Inside room P1.06, PMV, in the worst case, reaches the value of 1.8 (without units), while inside room P2.04, the maximum PMV is 0.9 (without units).

In the case of the smallest temperature differences occurring between midnight and morning (about 10:00), the difference between the rooms is around $0.5{ }^{\circ} \mathrm{C}$. In the case of the largest difference occurring around 17:30, the difference is $4{ }^{\circ} \mathrm{C}$. However, in the case of a room with no blinds, solar gains during the day are so great that the difference between the set temperature and the temperature in room $\mathrm{P} 1.06$ is as much as $5.5^{\circ} \mathrm{C}$. 


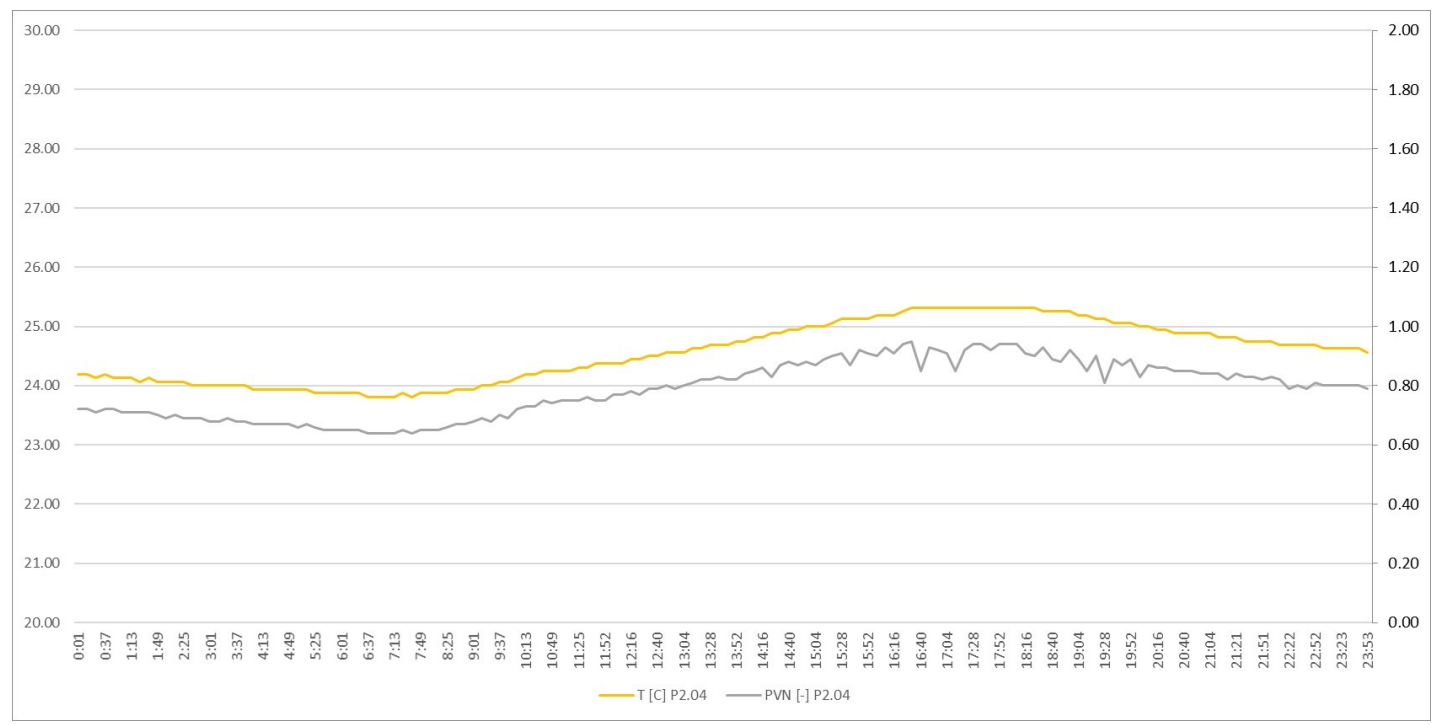

Figure 9. PMV and temperature relationship in the tested room P2.04 (1 August 2017).

In room P2.04, the lowest temperature $\left(23.81^{\circ} \mathrm{C}\right)$ was recorded around 7:00-8:00; the highest $\left(25.31^{\circ} \mathrm{C}\right)$ was recorded at around 17:00-18:00 (Figure 10). Figure 11 shows the internal temperature and outside temperature 1 August 2017. Humidity fluctuated from $66 \%$ to $69 \%$ (Figure 12). In room $\mathrm{P} 1.06$, the lowest temperature $\left(23.25^{\circ} \mathrm{C}\right)$ was recorded around 7:00-8:00 in the morning, the highest temperature (29.44 degrees) was recorded around 17:00-18:00 pm (Figure 10). Humidity fluctuated from $67 \%$ to $50 \%$ (Figure 12). The humidity stability in room P2.04 was much higher than in room P1.06, which had no blinds. Figure 13 shows the air velocity registered by sensors located in rooms P1.06 and P2.04. Figure 14 shows PMV graphs in tested rooms P106 and P204 (1 August 2017). Figure 15 indicates the differences in the PMV comfort factor between rooms P1.06 and P2.04.

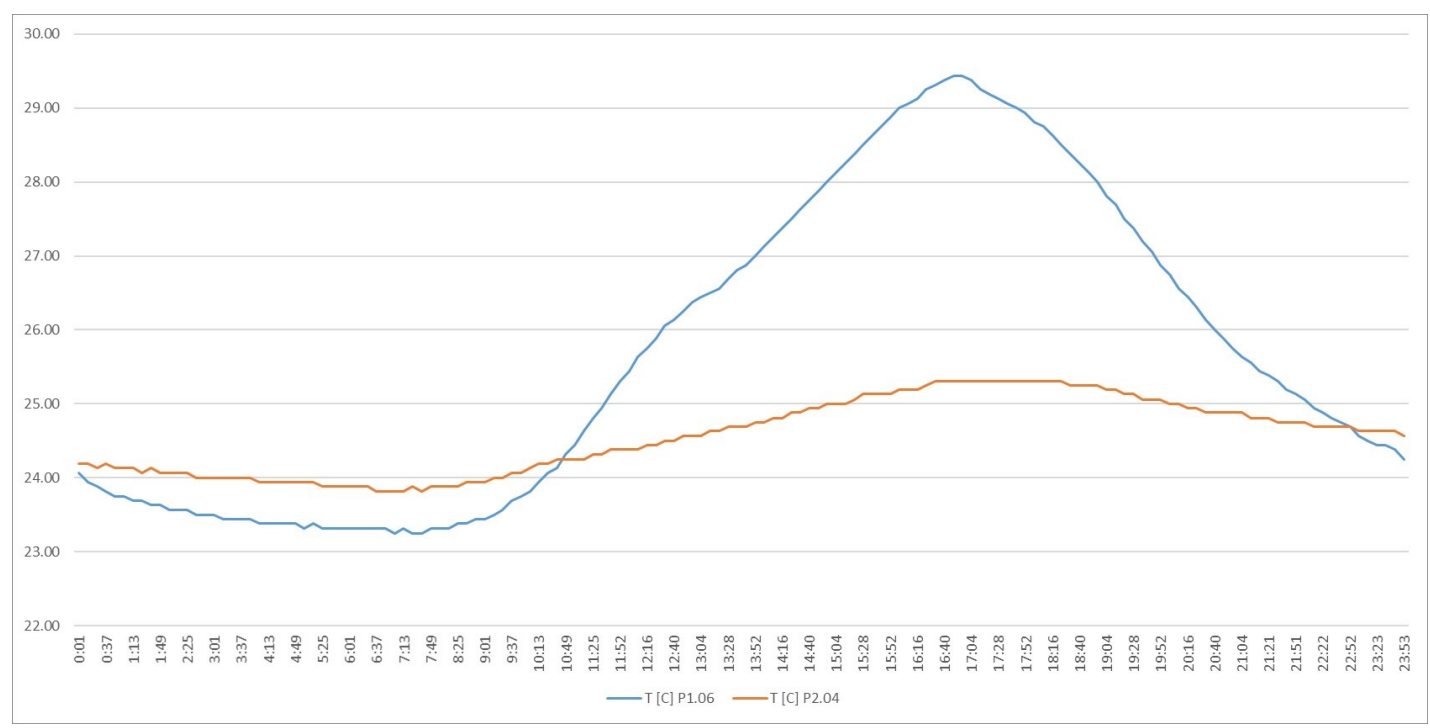

Figure 10. Temperature graphs in tested rooms P1.06 and P2.04 (1 August 2017).

Figure 14 shows a large difference in the feeling comfort for the occupants of both rooms.

In room P2.04, the comfort factor oscillates around (0.5-1.0). This means that the room can be classified in accordance with Polish Regulations [4] as comfortable in the highest class III (Table 2). In room P1.06, which was not equipped with a system of blinds, at around 17:00, the PMV indicator exceeds the thermal comfort scale PMV $>1.5$. Such rooms can only be classified as comfortable in class IV $($ PMV $<-0.7$, PMV $>0.7)$ (Table 2). 


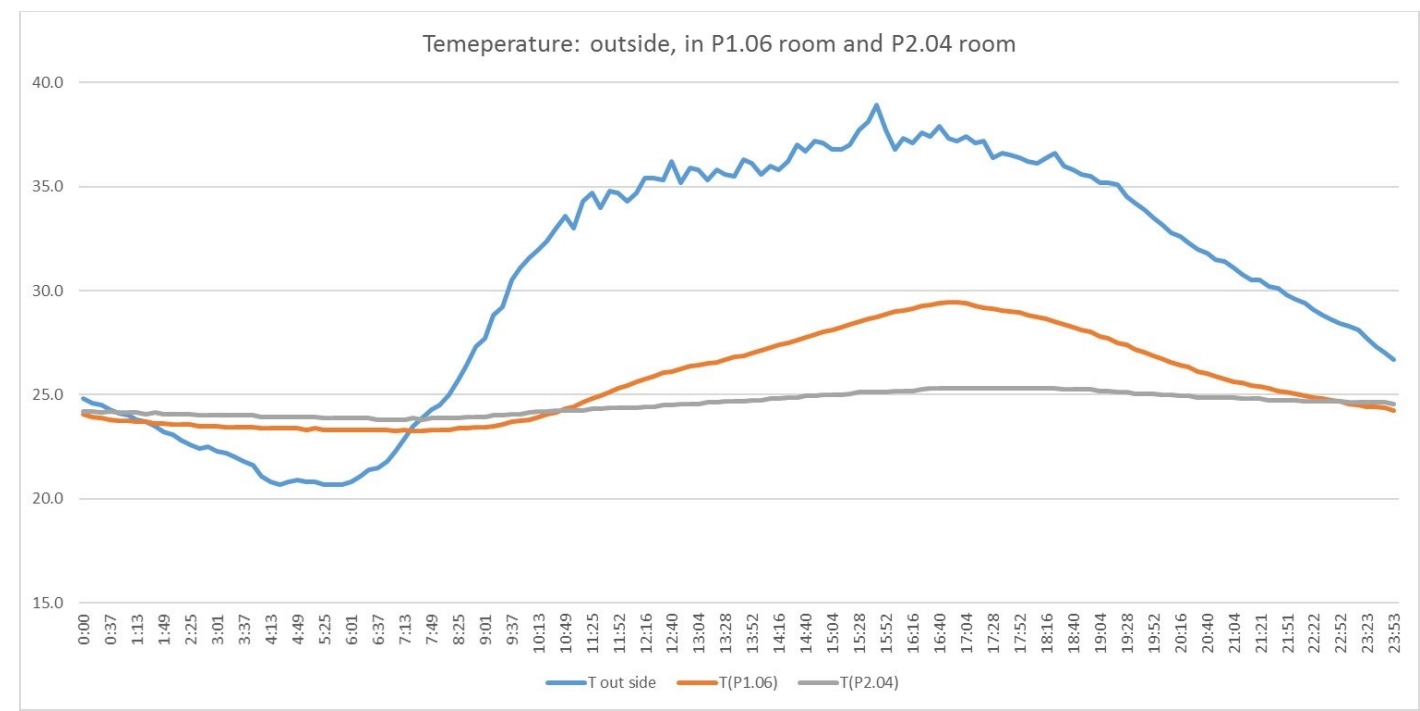

Figure 11. Date of measurements: 1 August 2017.

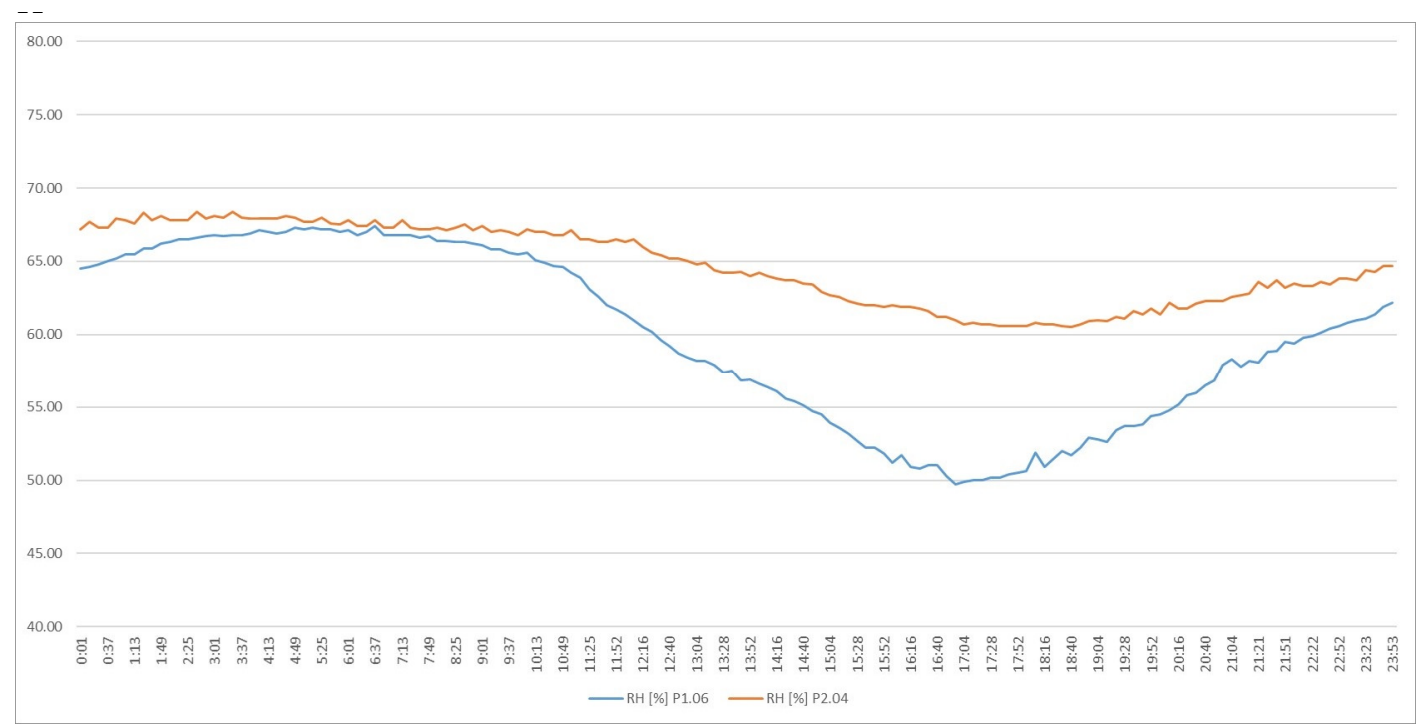

Figure 12. Humidity graphs in tested rooms P1.06 and P2.04 (1 August 2017).

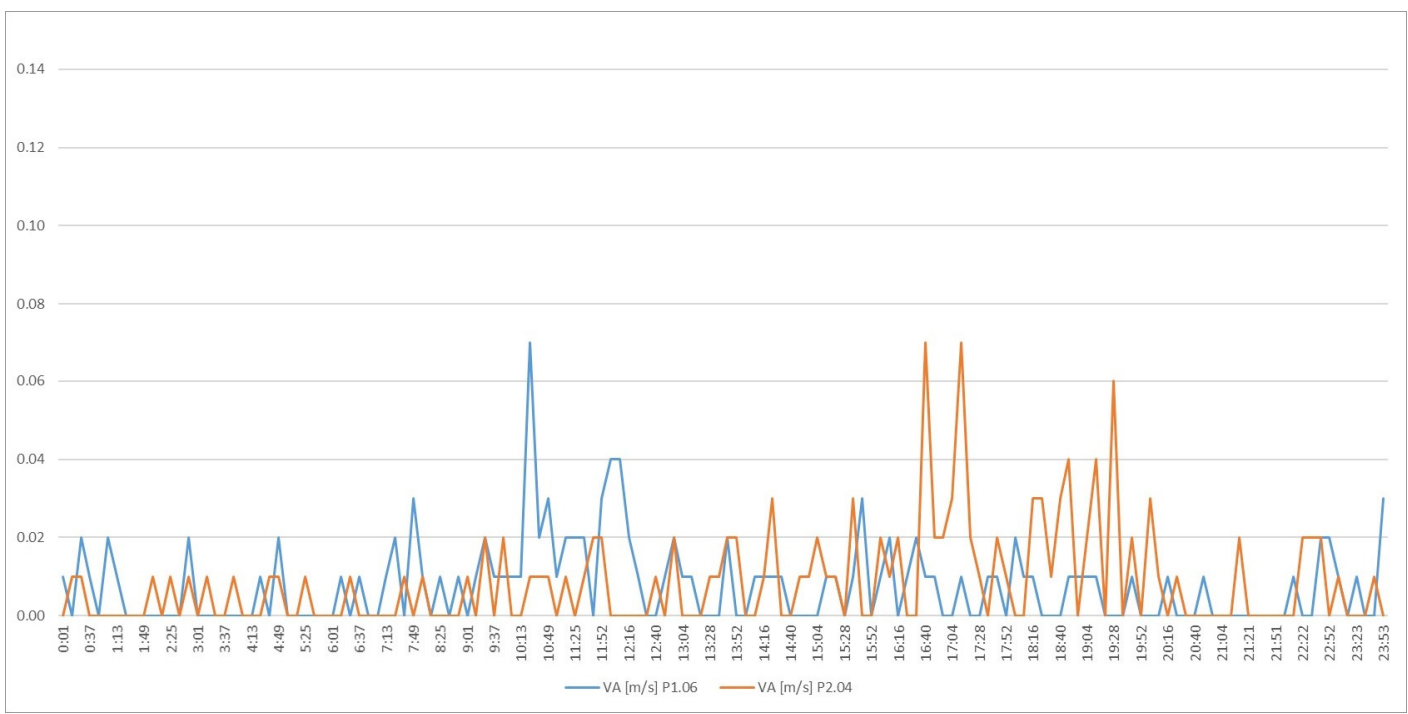

Figure 13. Air velocity in tested rooms P1.06 and P2.04 (1 August 2017). 


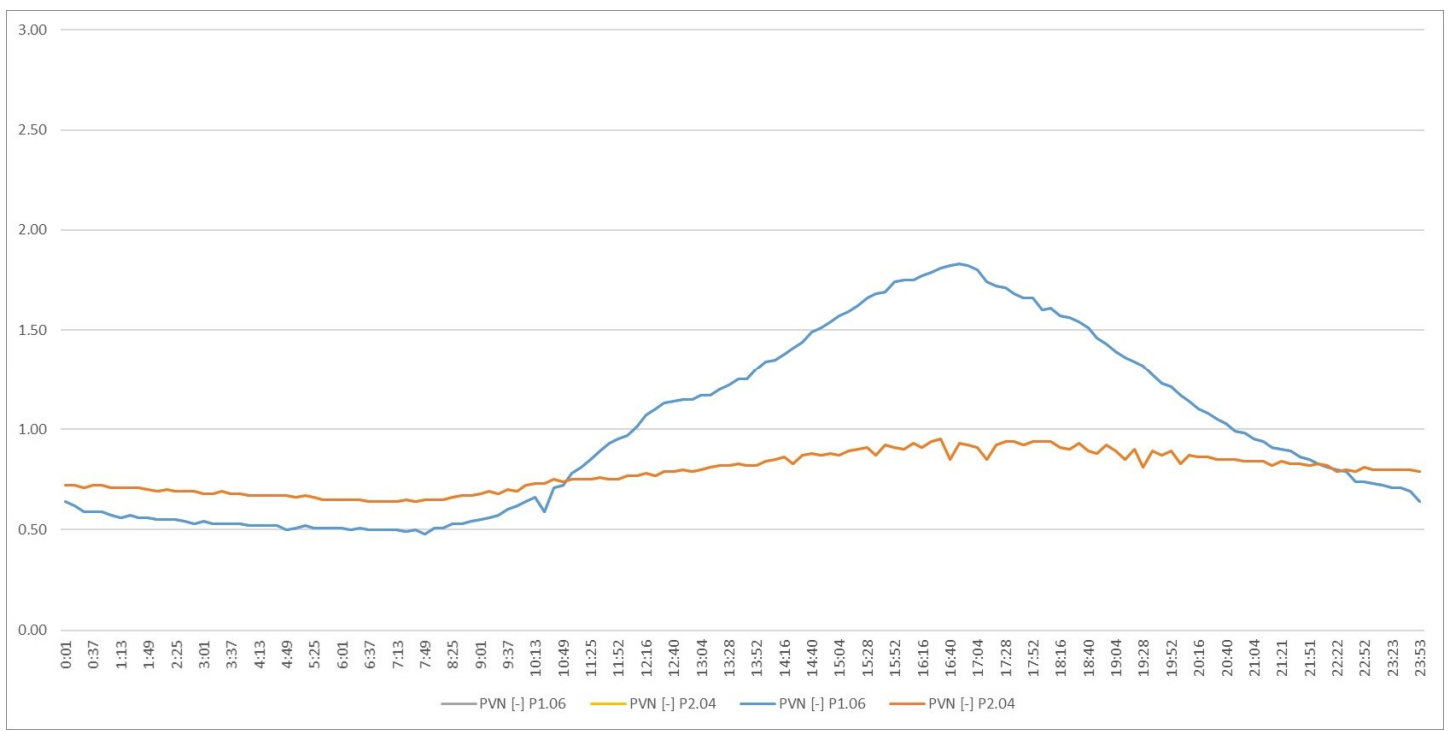

Figure 14. PMV graphs in tested rooms P106 and P204 (1 August 2017).

Table 2. Examples of recommended categories for designing heating and cooling strategies for buildings when using mechanical ventilation [16]. PPD: predicted percentage of dissatisfied people.

\begin{tabular}{ccc}
\hline \multirow{2}{*}{ Category } & \multicolumn{2}{c}{ Comfort Coefficients } \\
\cline { 2 - 3 } & PPD (\%) & PMV (Without Units) \\
\hline I & $<6$ & $-0.2<$ PMV $<+0.2$ \\
II & $<10$ & $-0.5<$ PMV $<+0.5$ \\
III & $<15$ & $-0.7<$ PMV $<+0.7$ \\
IV & $>15$ & PMV $<-0.7$ or PMV $>+0.7$ \\
\hline
\end{tabular}

Figure 15 presents the second of the comfort indicators: the predicted percentage of dissatisfied people (PPD). This indicates how many people would be dissatisfied with staying in the specific thermal conditions.

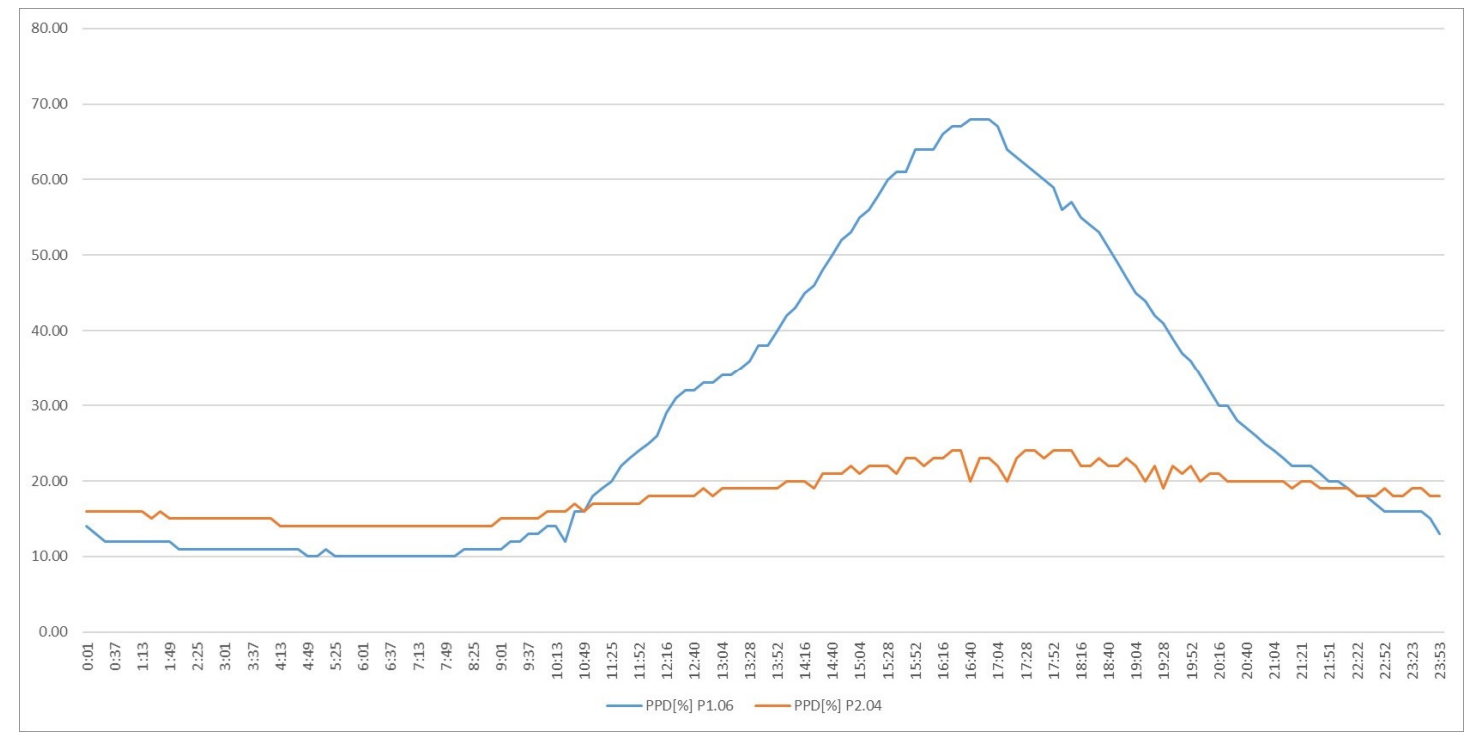

Figure 15. PPD plots in tested rooms P1.06 and P2.04 (1 August 2017).

The plot shows that during night-time hours and morning hours, until around 10:00, the PPD indicator oscillates around $10-17 \%$, which means that around $10-17 \%$ of occupants would be 
dissatisfied with the conditions both in room P1.06 and P2.04 during the working and afternoon hours. In the case of room P2.04, the number of dissatisfied people would be about $20-25 \%$. In room P1.06, the number of dissatisfied people would reach $69 \%$ around 16:00.

Figure 16 shows the influence of air velocity on the feelings of thermal comfort. Between 16:00-17:00, the thermal comfort sensations in room P2.04 improve, despite the stable temperature of about $25.3^{\circ} \mathrm{C}$. During this time, the air movement increased to approximately $0.8(\mathrm{~m} / \mathrm{s})$.

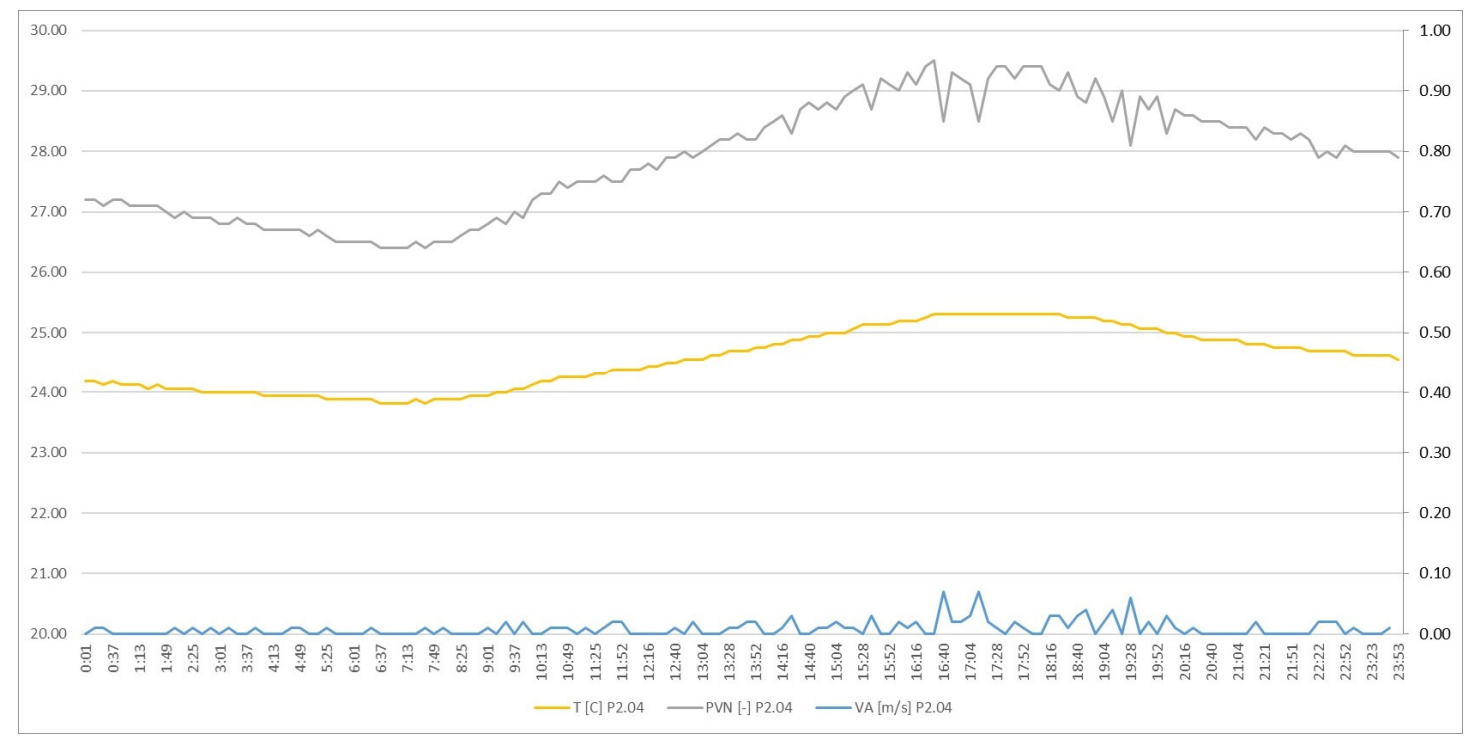

Figure 16. Temperature (T), PMV, and air velocity in P2.04 room (1 August 2017).

\subsection{Vibrational Comfort}

The vibrational comfort was measured in the same room in which other aspects of indoor conditions were investigated: thermal comfort, air quality, etc. (see Figure 17).

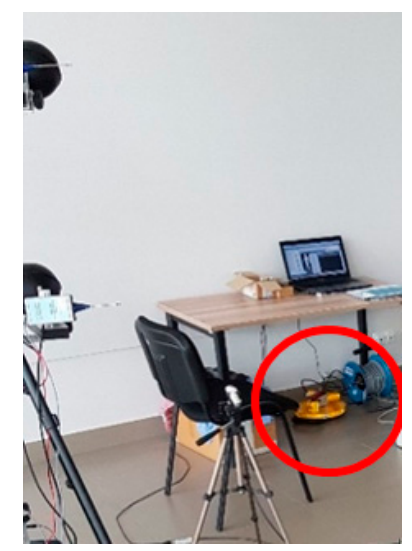

Figure 17. Room P1.06 and equipment for the measurement of indoor conditions.

The RMS procedure was performed to evaluate the vibrational comfort in the room. Over the whole day, 1447 events of over $3 \mathrm{~cm} / \mathrm{s}^{2}$ were recorded. Some of these vibrational events were disturbed and confounded as a result of internal vibrations caused by the residents of the building. Internal excitation signals were rejected from further analysis; however, over 1000 vibrational events were analyzed. In almost 30 events, the human perception threshold was exceeded (e.g., Figure 18). Exceeding always occurs in the ' $\mathrm{z}$ ' direction.

In some cases, exceeding the comfort is not visible from the graph (see Figure 18). In this kind of situation, the WODL ratio (e.g., Human Vibration Perceptivity Ratio) proposed in 
PN-B-02171:2017-06 [29] could be useful. This is the maximum ratio of the acceleration RMS value obtained from the analysis to the acceleration RMS value that is equivalent to the threshold for the human perception of vibration (in the same $1 / 3$ octave band) chosen from each $1 / 3$ octave band. The advantage of such a coefficient is that the result of the analysis from the frequency band is not independent, since the WODL directly shows how many times the threshold for human vibration has been exceeded:

$$
W O D L=\max \left(\frac{a_{R M S}}{a_{z}}\right)
$$

where: aRMS - acceleration RMS (Root Mean Square) value obtained from analysis; az-acceleration RMS value equivalent to the threshold for the perception of vibration in a z-direction in the same 1/3 octave band as in aRMS.

In Table 3, the WODL coefficient is listed for two frequency bands in which exceeding the threshold of perception or comfort level can occur.

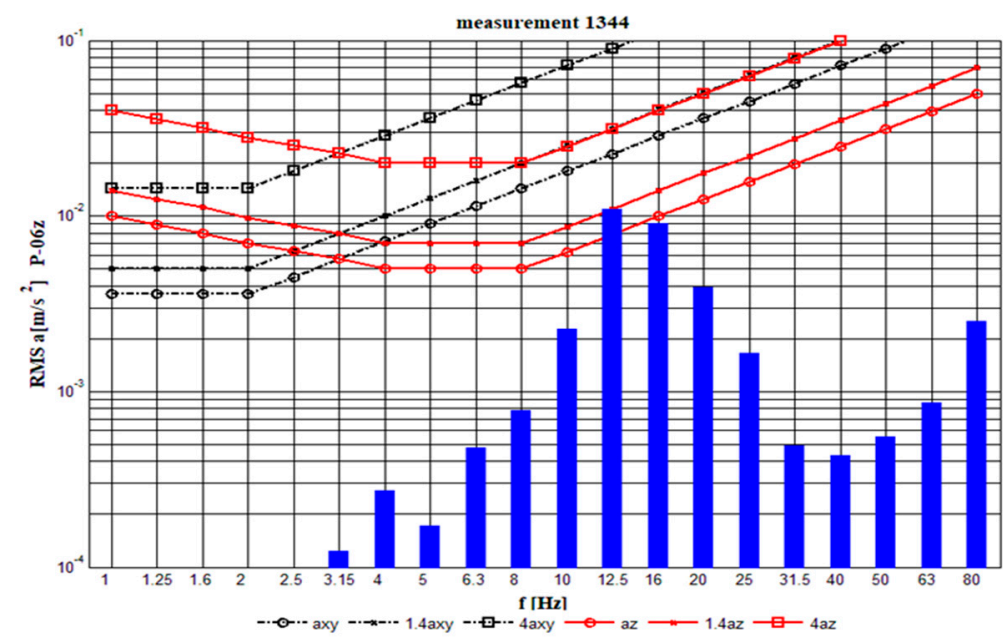

Figure 18. RMS analysis in $1 / 3$ octave bands in the ' $z$ ' direction.

Table 3. WODL values in one third of the frequency bands.

\begin{tabular}{cc}
\hline $\mathbf{f}(\mathbf{H z})$ & WODL (Without a Unit) \\
\hline 12.50 & 1.41 \\
16.00 & 0.91 \\
\hline
\end{tabular}

The results of the WODL analysis show that, for a frequency of $12.5 \mathrm{~Hz}$, the WODL coefficient is 1.41 , which suggests that the vibrational comfort level is exceeded; for a frequency of $16 \mathrm{~Hz}$, the WODL coefficient is 0.91 , which means that the human perception threshold was exceeded in this frequency band, which is not obvious from Figure 19. For five vibrational events, not only was the human perception threshold exceeded during the night, so was the human comfort level, which is 1.4 according to PN-B-02171:2017-06 [29] and ISO 2631-2: 2003 [30] (Figure 19). It is worth noting that the MLBE building is an office building, which is unoccupied during the night. At the same time, it should be remembered that the room in which the indoor condition measurements were made is located on the third story of the five-story building. The measurements presented in this paper were made in the rooms that the occupants requested. Since exceeding the comfort level is observed on the third story, additional measurements on the above stories should be made in the future. 


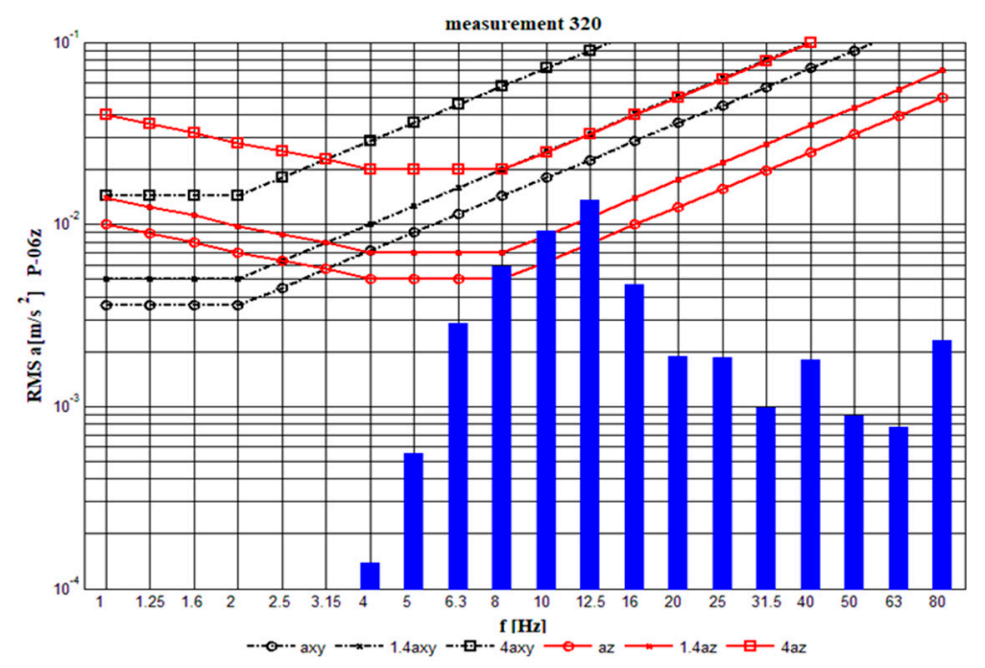

Figure 19. RMS analysis in $1 / 3$ octave bands in the ' $z$ ' direction.

\section{Discussion}

Referring to the work of Dudzińska [9], where the thermal comfort in a public building in Poland was checked, the maximum temperature in the case of $100 \%$ glazing was over $29{ }^{\circ} \mathrm{C}$. Similar results were obtained by the present authors in the case of tests in room P1.06. The maximum temperature obtained on 1 August 2017, in a room with $100 \%$ southern façade glazing, was $29.41{ }^{\circ} \mathrm{C}$. However, in a room with similar parameters equipped with an external blinds system, the internal air temperature was $25.3^{\circ} \mathrm{C}$, which is still a comfortable temperature for light work in a sitting position during the summer $\left(23.9-26.7^{\circ} \mathrm{C}\right)$ according to Health and Safety Assistant portal [14].

In the article (Dudzińska) [1], the author analyzed the influence of sunshades on thermal comfort in a passive public building. The author analyzed cases of windows with and without blinds, as well as light breakers. The simulations were carried out for the period from 1 May to 30 August 2002. On the hottest days, the PMV comfort index reached values from 2.0 to 2.3.

The results that were collected by the authors of this article indicate that in the case of room P1.06, the highest value of PMV was about 1.8, while the room with external blinds showed the highest PMV values, ranging from 0.8 to 1.0 .

A comparison of the results of the authors' research with other publications shows similar values of maximum internal temperatures and PMV indicators for rooms without sunshades. However, for rooms with sunshades, the actual test results are lower than the results that were obtained in simulations.

This article supports that investing in additional elements such as shutters and shades to ensure thermal comfort at an appropriate level is worth considering, and might reduce the costs that are associated with the operation of the building.

The human perception of vibration was investigated according to the RMS method, which is the basic method of evaluation in many national standards and the ISO standard/ISO 2631-1/. The results show that the comfort limit is not exceeded, but vibrational human perception threshold in some dynamical events is exceeded. Similar measurements were made by Tamura et al. [31], Kwok et al. [32], Waddington et al. [33].

To sum up the above sections and address the contribution and implications for policy and practice:

- The tests that were carried out by the authors confirmed that the application of only the energy efficiency requirements contained in Polish Regulation [4] does not ensure the comfort of use of NZEB buildings. The Technical and Building Conditions [4] that are applicable in Poland and concern the design of buildings should include requirements (and not recommendations) of using sun blinds, especially in buildings with large glazing on the south side. 
- The second postulate resulting from the conducted research is the necessity to introduce requirements ensuring vibratory comfort to standards defining the assurance of the quality of the internal environment (PN-EN 15251: 2012 standard) [5]. Vibration comfort is just as important as thermal, acoustic, and visual comfort. The research that was carried out by the authors is a guide for designers to pay more attention to ensuring the comfort of using NZEB and passive buildings.

\section{Conclusions}

The work presents the chosen results of tests carried out in the experimental building of the MLBE. Using the example of two rooms, one of which was designed in such a way as to allow fulfilling the requirements for NZEB objects, thermal and vibration comfort tests were carried out.

The performed tests clearly show the advantage of the objects that were specially designed to ensure minimal energy consumption in comparison to standard solutions, which are currently used in Poland. On the basis of these tests, the savings in energy that are required to provide thermal comfort in the room were confirmed. A larger stability of thermal conditions over $24 \mathrm{~h}$ was also achieved. During critical hours (14:00-15:00), 100\% of people staying in a standard room (1.04) felt discomfort, while in room 2.04, the number of people feeling discomfort did not exceed $10 \%$. Thermal comfort was established on the basis of EU regulations instead of occupants' questionnaires, which are sometimes used to evaluate thermal comfort in low-energy buildings [28]. Despite differences in evaluation methods, the results obtained during MLBE measurement are convergent with results for similar buildings [34].

In the currently prevailing architectural trend in the design of office buildings, the entire interior of the building is displayed using glass elevations. Due to costs, solutions in the form of solar protection systems (as in room 2.04) instead rely on the efficiency of air conditioning systems. The tests have shown that such an approach is flawed, as in room 1.04-despite air conditioning-it was not possible to achieve thermal comfort. Such an approach causes an increase in energy consumption above the average work of the heating system, yet in no way does it provide thermal comfort, exposing the people staying inside to discomfort and poor health.

Along with thermal comfort tests, vibration comfort tests were carried out. Buildings of zero-energy consumption are designed in such a way as to ensure the quality of the internal conditions, such as temperature, air quality (PM 10, PM 2.5), humidity, etc. This frequently requires certain architectonic and constructional solutions leading to a lowering of solutions; this can have the unfortunate side effect of decreasing the vibrational comfort. Similarly, as with thermal comfort, vibrational comfort is also not taken into consideration when designing a building, and the tests clearly show that exceeding comfort in this respect may cause health problems of psychological and physical natures.

The tests have proved that despite having implemented architectonic and construction solutions for NZEBs, it is possible to optimize the construction layout in such a way as to provide vibrational comfort during the day. During the night, when there are no people in the building, the vibration comfort is exceeded. The authors will also carry out tests on other buildings to collect a larger group of data. It seems that the results of these tests could be the basis for introducing additional requirements in building regulations in Poland.

Another problem that will be analyzed in the subsequent articles is the issue pertaining to comfort monitoring in terms of the following aspects: thermal comfort, acoustic comfort, and vibrational comfort [35-37]. The selection of gauges and monitoring systems is another crucial problem. In the subsequent articles, the authors will present research that was conducted in the experimental building of the Malopolska Laboratory of Energy Efficient Building. This research will contribute significantly to the issues of designing low-energy (NZEB and passive) buildings. 
Author Contributions: Conceptualization, M.F.-C., A.K.-K.; Methodology, T.T., M.F.-C., A.K.-K., M.F., J.G.; Formal Analysis, M.F.-C., A.K.-K., F.P.; Investigation, M.F.-C., A.K.-K., F.P.; Visualization, M.F.-C., A.K.-K., F.P.; Supervision, T.T.

Funding: This research received no external funding.

Acknowledgments: The authors would like to acknowledge the Malopolska Laboratory of EnergyEfficient Building.

Conflicts of Interest: The authors declare no conflicts of interest.

\section{References}

1. Dudzińska, A. Effectiveness of sunshades in shaping thermal comfort in a passive public building. J. Civ. Eng. Environ. Arch. 2015, XXXII, s39-s48.

2. The European Parliament and the Council of the European Union. Directive 2010/31/EU of the European Parliament and of the Council of 19 May 2010 on the Energy Performance of Buildings (Recast); the European Union: Brussels, Belgium, 2010.

3. Criteria for the Passive House, EnerPHit and PHI Low Energy Building Standard. Available online: https: / / passiv.de/downloads/03_building_criteria_en.pdf (accessed on 1 October 2018).

4. Regulation of the Minister of Infrastructure and Construction Regarding Technical Requirements Which Should Be Met by Buildings and Their Location; Official Journal of the Republic of Poland. Available online: http:/ / prawo.sejm.gov.pl/isap.nsf/download.xsp/WDU20150001422/O/D20151422.pdf (accessed on 11 October 2018).

5. Indoor Environmental Input Parameters for Design and Assessment of Energy Performance of Buildings Addressing Indoor Air Quality, Thermal Environment, Lighting and Acoustics. Available online: http://www.cres.gr/greenbuilding/PDF/prend/set4/WI_31_Pre-FV_version_prEN_ 15251_Indoor_Environment.pdf (accessed on 17 October 2018).

6. Kisilewicz, T. Overheating of Low-Energy Buildings. Available online: http://beta.nis.com.pl/userfiles / editor/nauka/122013_n/Kisilewicz_12-2013.pdf (accessed on 17 October 2018).

7. Bzowska, D. Risk of Overheating of Heat Insulated Buildings in the Summer Time. J. Civ. Eng. Environ. Arch. 2016, XXXIII, s43-s52.

8. Bzowska, D. Changes in temperature in buildings in response to the changing climate. Tech. Trans. 2012, 3, 37-44. (In Polish)

9. Dudzińska, A. Analysis of the influence of the surface of transparent partitions on the microclimate of a passive public building. J. Civ. Eng. Environ. Arch. 2017, XXXIV, s139-s146. [CrossRef]

10. Fanger, P.O. Thermal Comfort: Analysis and Applications in Environmental Engineering; Danish Technical Press: Copenhagen, Denmark, 1970.

11. Shukuya, M. Exergetic Aspect of Human Thermal Comfort and Adaptation. In Sustainable Houses and Living in the Hot-Humid Climates of Asia; Springer: Singapore, 2018; pp. 123-129.

12. Prek, M. Exergy analysis of thermal comfort. Int. J. Exergy 2004, 1, 303-315. [CrossRef]

13. Kubota, T.; Rijal, H.R.; Takaguchi, H. (Eds.) Sustainable Houses and Living in the Hot-Humid Climates of Asia Project: Research on Human-Adaptable Built Environment Suiting to Local Climate with the Use of Natural Exergy; Springer: Singapore, 2018; pp. 13-23. [CrossRef]

14. Praca w Wysokich Temperaturach. Available online: https://asystentbhp.pl/praca-w-wysokichtemperaturach-1041/ (accessed on 17 October 2018).

15. American Society of Heating, Refrigeation and Air-Conditioning Engineers. Thermal Environmental Conditions for Human Occupancy. Available online: https:/ /www.ashrae.org/technical-resources / bookstore/thermal-environmental-conditions-for-human-occupancy (accessed on 17 October 2018).

16. ISO. Ergonomics of the Thermal Environment-Analytical Determination and Interpretation of Thermal Comfort Using Calculation of the PMV and PPD Indices and Local Thermal Comfort Criteria; International Organization for Standarization: Geneve, Switzerland, 2005.

17. Nicol, F.; Humphreys, M.; Sykes, O.; Roaf, S. Standards for Thermal Comfort; Tailor \& Francis: London, UK, 2015; ISBN 041902.04202.

18. Fedorczak-Cisak, M.; Furtak, M.; Kotowicz, A. Aspects and implementation of low-energy buildings design. J. Natl. Univ. Lviv Polytech. 2016, 1, 253-259. 
19. Fedorczak-Cisak, M.; Kowalska-Koczwara, A.; Romańska-Zapała, A. Energy Simulations of Residential Building Using a Dynamic Energy-Balanced Software. Available online: http:/ / www.inase.org/library/ 2015/zakynthos/bypaper/CIMC/CIMC-36.pdf (accessed on 17 October 2018).

20. Parsons, K. Human Thermal Environments; CRC Press: London, UK, 2003; ISBN 978-1-4665-9599-6.

21. Öhrström, E.; Skånberg, A.-B. A field survey on effects of exposure to noise and vibration from railway traffic, part I: Annoyance and activity disturbance effects. J. Sound Vib. 1996, 193, 39-47. [CrossRef]

22. Trollé, A.; Marquis-Favre, C.; Parizet, E. Perception and Annoyance Due to Vibrations in Dwellings Generated from Ground Transportation: A Review. J. Low Freq. Noise Vib. Act. Control 2015, 34, 413-457. [CrossRef]

23. Han, J.; Kwon, S.; Chun, C. Indoor environment and passengers' comfort in subway stations in Seoul. Build. Environ. 2016, 104, 221-231. [CrossRef]

24. Liang, L.; Tian, S.; Xiao, P.; Jiang, X.; Xiao, L. Shenyang Urban Noise Monitoring-In Shenyang Subway Line 1 and Subway Line 2 for Example. J. Liaoning Univ. (Natural Sci. Ed.) 2015, 2015-01. Available online: http:/ / en.cnki.com.cn/Article_en/CJFDTotal-LNDZ201501017.htm (accessed on 17 October 2018).

25. Cik, M.; Lercher, P. Ground-borne vibrations, sounds and secondary airborne sounds from tramways: a psychoacoustic evaluation including health. In Proceedings of the INTER-NOISE and NOISE-CON Congress and Conference, Melbourne, Australia, 16-19 November 2014; pp. 1-9.

26. Croy, I.; Smith, M.G.; Waye, K.P. Effects of train noise and vibration on human heart rate during sleep: An experimental study. BMJ Open 2013, 3, e002655. [CrossRef] [PubMed]

27. Smith, M.G.; Croy, I.; Ögren, M.; Waye, K.P. On the Influence of Freight Trains on Humans: A Laboratory Investigation of the Impact of Nocturnal Low Frequency Vibration and Noise on Sleep and Heart Rate. PLoS ONE 2013, 8, e55829. [CrossRef] [PubMed]

28. ISO. Ergonomics of the Thermal Environment-Devices for Measuring Physical Quantities; International Organization for Standarization: Geneve, Switzerland, 1998.

29. Polish Standard Committee. Evaluation of Human Exposure to Vibration in Buildings; Polish Standard Committee: Warsaw, Poland, 2017.

30. ISO. Guide to the Evaluation of Human Exposure to Whole Body Vibration. Part 2-Vibration in Buildings; International Organization for Standardization: Geneva, Switzerland, 2003.

31. Tamura, Y.; Kawana, S.; Nakamura, O.; Kanda, J.; Nakatà, S. Evaluation perception of wind-induced vibration in buildings. Struct. Build. 2006, 159, 1-11. [CrossRef]

32. Kwok, K.C.S.; Hitchcock, P.A.; Burton, M.D. Perception of vibration and occupant comfort in wind-excited tall buildings. J. Wind Eng. Ind. Aerodyn. 2009, 97, 368-380. [CrossRef]

33. Waddington, D.C.; Woodcock, J.; Peris, E.; Condie, J.; Sica, G.; Moorhouse, A.T.; Steele, A. Human response to vibration in residential environments. J. Acoust. Soc. Am. 2014, 135, 182-193. [CrossRef] [PubMed]

34. Raish, J. Thermal Comfort: Designing for People; Lang, W., McClain, A., Eds.; School of Architecture, The University of Texas: Austin, TX, USA, 2008.

35. Huang, Q.; Lu, C.; Shaurette, M.; Cox, R. An environmental network of solar energy sensors for monitoring buildings. In Proceedings of the 28th International Symposium on Automatics and Robotics in Construction, Seoul, Korea, 29 June-2 July 2011; pp. 1376-1380.

36. Huang, Q.; Ge, Z.; Lu, C. Estimation of occupancy in intelligent buildings using sound processing techniques. In Proceedings of the 16th International Conference on Calculation in Civil Engineering and Construction, Hong Kong, China, 11-13 December 2016; pp. 1413-1420.

37. Habash, G.; Chapotchkine, D.; Fisher, P.; Rancourt, A.; Habash, R.I.; Norris, W. Sustainable Design of a Nearly Zero Energy Building Facilitated by a Smart Microgrid. J. Renew. Energy 2014, 2014, 725850. [CrossRef]

(C) 2018 by the authors. Licensee MDPI, Basel, Switzerland. This article is an open access article distributed under the terms and conditions of the Creative Commons Attribution (CC BY) license (http://creativecommons.org/licenses/by/4.0/). 